\title{
POSSIBILITIES OF UAS FOR MARITIME MONITORING
}

\author{
A.Klimkowska ${ }^{\text {a }}$, I. Lee ${ }^{\mathrm{a}}$, K. Choi ${ }^{\mathrm{a}}$ \\ ${ }^{a}$ Dept of Geoinformatics, University of Seoul, 163, Seoulsiripdae-ro, Dongdaemun-gu Seoul, Korea - \\ anna.maria.klimkowska@gmail.com, iplee@uos.ac.kr, shale@uos.ac.kr
}

Commission I, ICWG I/Vb

KEY WORDS: maritime monitoring, UAV, UAS, remote sensing, sensors

\begin{abstract}
:
In the last few years, Unmanned Aircraft Systems (UAS) have become more important and its use for different application is appreciated. At the beginning UAS were used for military purposes. These successful applications initiated interest among researchers to find uses of UAS for civilian purposes, as they are alternative to both manned and satellite systems in acquiring highresolution remote sensing data at lower cost while long flight duration. As UAS are built from many components such as unmanned aerial vehicle (UAV), sensing payloads, communication systems, ground control stations, recovery and launch equipment, and supporting equipment, knowledge about its functionality and characteristics is crucial for missions. Therefore, finding appropriate configuration of all elements to fulfill requirements of the mission is a very difficult, yet important task. UAS may be used in various maritime applications such as ship detection, red tide detection and monitoring, border patrol, tracking of pollution at sea and hurricane monitoring just to mention few. One of the greatest advantages of UAV is their ability to fly over dangerous and hazardous areas, where sending manned aircraft could be risky for a crew. In this article brief description of aerial unmanned system components is introduced. Firstly characteristics of unmanned aerial vehicles are presented, it continues with introducing inertial navigation system, communication systems, sensing payloads, ground control stations, and ground and recovery equipment. Next part introduces some examples of UAS for maritime applications. This is followed by suggestions of key indicators which should be taken into consideration while choosing UAS. Last part talks about configuration schemes of UAVs and sensor payloads suggested for some maritime applications.
\end{abstract}

\section{INTRODUCTION}

Unmanned Aircraft Systems have a long history in supporting warfare missions. Unmanned aerial platforms has been used for military reconnaissance missions since appropriate photographic sensors were developed. Successful application of UAS systems for military purpose aroused interest among researchers in using UAS for science missions. A milestone in the adaptation of UAS to support scientific research was NASA's Environmental Research Aircraft and Sensor Technology (ERAST) program started in 1990s. The program was held to develop slow-flying, cost-effective UAS capable of long-duration science missions. As a result of this project, unmanned systems such as Altus, Pathfinder and Helios are used in environmental research and to carry on atmospheric measurements. During use, UAS systems have been found to be useful for environmental monitoring and protection, homeland protection, monitoring of critical infrastructure as well as a great tool for disaster prevention and management (Skrzypietz, T., 2012). Systems can be successfully used on dangerous missions, where direct monitoring by humans is not possible due to occurred conditions.

\section{UAS SYSTEMS}

A UAS is something more than the unmanned aircraft. The main components which form the system are the unmanned aircraft which can fly autonomously or be remotely piloted, communications systems, payloads, ground control stations, recovery and launch equipment as well as support equipment. In this part of the article elements of UAS are briefly described.

\subsection{UAV Classification}

Nowadays, different unmanned aerial vehicles (also known as drone, remotely piloted aircrafts (RPA), remotely piloted vehicles (RPV) to list few) are available on the market, which made it easier to choose one that is most suitable for mission purposes. However, because of the variety of characteristics describing unmanned aerial vehicles, it is hard to categorize them unequivocally. Nonetheless, four attributes can be distinguished to categorize unmanned aerial vehicles:

- Flight altitude

- Endurance

- Range

- Maximum Take-Off Weight (MTOW)

Table 1 shows classification of the UAVs based on characteristics mentioned above. This categorization is just one of many that can be used to group UAVs. Another approach to classify unmanned aerial systems is shown below:

Fixed-wing UAVs: are represented by unmanned airplanes (with wings). The main advantage of this system is its simple structure (comparing to rotary wing) which result in less complicated maintenance and repair process. What is more, this characteristics allow for longer flight duration and higher speed which has an effect on surveying of larger areas. Fixed-wing solutions are capable of carring greater payloads for longer distances, therefore bigger sensors can be attached to an aircraft, which gives wider field of applications. A fixed wing vehicle need a runway or catapult for take-off and landing, 
which is considered as the only disadvantage of a system. However, solutions such as VTOL (vertical take-off/landing) or STOL

(short take-off/landing) are popular options to help eliminate this problem. As said, the greatest disadvantage of using fixedwing solutions is related to take-off and landing properties, system has another drawback. It is its need for air moving over the wings to produce lift and maintain system on a constant forward motion.

Rotary-wing UAVs: also called rotorcraft UAVs, consist of 2 or 3 rotor blades that revolve around a fixed mast (known as a rotor). Rotary-wing UAVs are available in many different configurations. Helicopter consist of one rotor, tricopter is built of 3 rotors, quadratoper is lifted and propelled by four rotors, hexacopter by 6 rotors and octocopter consist 8 rotors. All this systems can create different configurations where each of them has unique characteristic advantages and disadvantages. Rotor blades work the same way as a fixed wing. However, compared with a fixed-wing solution, there is no need to produce airflow over the blades by constant aircraft forward movement. In the rotary-wing solution blades are in constant movement which leads to the generation of lift. Among the advantages of using rotary-wing vehicles one of the greatest is its ability to take-off and land vertically. It means that no large area is needed for UAV take-off/landing. However, two limitations of rotary wingUAVs are worth mentioning. First is their complex mechanical and electronic construction which lead to more complicated repair and maintenance process. This translates into a reduction in mission time which can contribute to increased operational costs. Rotary-wing systems are characterized with lower speed and shorter flight ranges. This disadvantage contributes to an increase in the number of flights over the area of interest, which in turn increase time and cost of the operation.

Blimps, balloons and kites: these vehicles are characterized by being lighter than air and long endurance, low flying speed and rather big size

Flapping-wing UAVs: these vehicles, with small and flexible/morphing wings, are inspired by flying insects and birds. The reason for small autonomous flying robots was motivated by the need of aerial reconnaissance inside buildings, confined spaces as well as within dangerous, dirty and dull areas (J. Mueller, T.J., 2001).
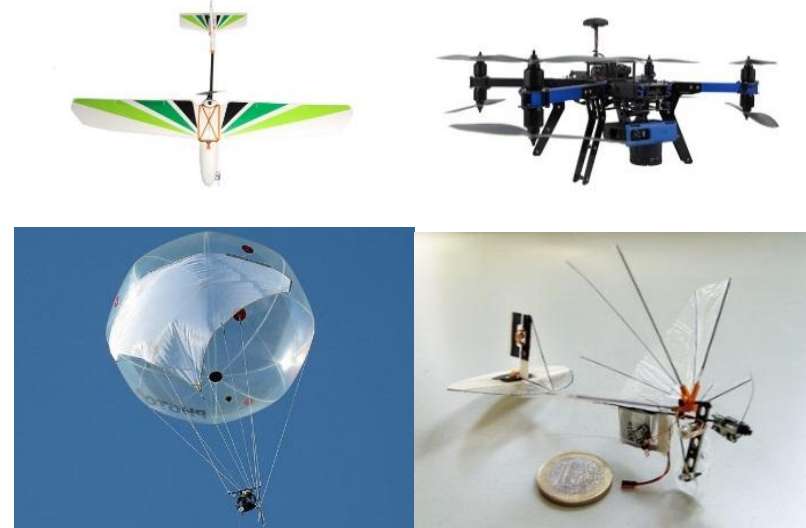

Fig.1 a) Fixed-wing UAV: 3D Robotics Aero M, b) Rotarywing UAV: 3D Robotics X8-M (source for a and b:

https://uavsystemsinternational.com/), c) Balloon: DSLR Aerial Photography System (http://www.rc-zeppelin.com/index.html), d) Flapping-wing UAV: DelFly Micro (http://www.delfly.nl/index.html)

\subsection{Global Positioning System (GPS) / Inertial Navigation System (INS)}

GPS and an inertial measurement unit (IMU) compose the inertial navigation system (INS) which provides navigation solution for autopilot and other systems of UAS. The INS can occur in two different combinations: as a stand-alone unit or can be integrated with the autopilot. Except navigation application, INS can be used to stabilize payloads and support sensor pointing estimation.

\subsection{Communication systems (data link)}

Communication technology is part of the UAS responsible for data distribution between system elements and to external units. The principal issues of communication systems are adaptability, flexibility, security as well as cognitive controllability of frequency, bandwidth and data/information flow (Nonami, K. et al., 2010). UAS communication is mainly useful in terms of safety when it comes to integration between UAS and Air Traffic Control (ATC). Many elements can compose communication systems and be integrated in various configurations. Figure 2. shows some of the common elements comprising such system.

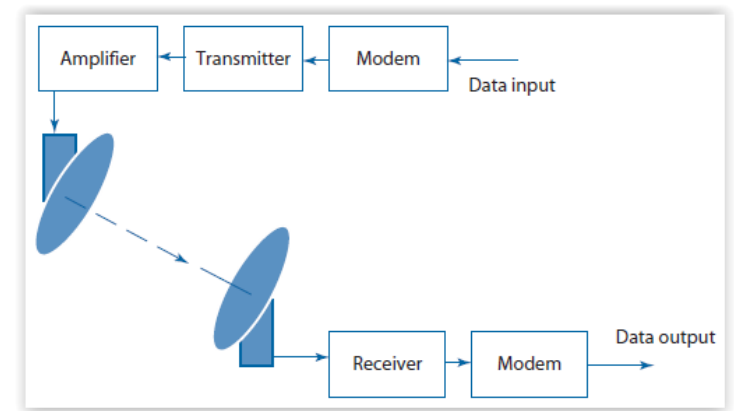

Block diagram of a sample communication system (Gundlach, J., 2012)

Communications system types:

- Command and control (C2) - data links allow the operator to guide and control the unmanned vehicle state. The uplink is used to command the unmanned vehicle, while the downlink is used for ground receipt of status and condition information.

- Payload link - this link transmits information from the unmanned vehicle to a ground-receiver device. The payload data link is usually critical for missions but not for flights.

- Air-to-air communication - UASs can cooperate with other airborne platforms, which demand air-to-air communication between the platforms.

- Voice relay - UASs share the same space with manned aircrafts that is why they are required to behave like the manned vehicles. Pilot of manned aircraft can have a dialog with the control tower, these are voice communications with the air traffic control (ATC) system. A great benefit from this solution is possibility to be heard by other aircrafts, which provide information and increase situational awareness.

- Transponders - play an important role in airspace management and are very useful to avoid air-to-air collision. Transponders can be used to transmit data on the unmanned vehicle position when one is 
interrogated.

\subsection{Control Types:}

As the main assumption of unmanned aerial vehicle concerns removing operator from the cockpit of the vehicle, control over it has to be conducted by other means. Three possibilities of remote control over an aircraft can be distinguished:

- Ground control: also known as Remotely Piloted Vehicles ("RPVs") need the operator to provide constant input information. A ground control station (GCS) is a control center located on land or sea to provide the facilities for operators of unmanned vehicles in the space or air.

- Semi-autonomous: in this case operator do not need to be engaged in the aircraft flight during whole operation, however he/she needs to have full control over the aircraft during pre-flight, take-off, landing, weapons employment and important maneuvers. In the other stages of the flight, autopilot can be used to operate the aircraft. The vehicle will follow the programmed waypoints.

- Fully autonomous: here control relies on controlling unmanned vehicle only by the on-board computer without human participation. It means no human input is necessary to perform an objective following the decision to take-off. What is more, UAV can assess its condition, status; command, configuration and control onboard the aircraft.

\subsection{Sensing Payloads}

Each application of UAV require different combinations of payload attached to the aircraft. Finding appropriate sensor is a difficult task, as the UAV is often predefined. The UAS operators and developers have to find a way to fit a remote sensing sensor into a given UAV weight, volume and power specifications remembering that every application has specific requirements such as resolution, accuracy or sensing bandwidth. It is a hard and complex task to solve. Fortunately the systems available on the market are very diverse, from low cost mass-market, through amateur and professional, ending at those specifically designed for photogrammetry and remote sensing missions which gives possibility in finding the best matching option. Remondino (2011) present comprehensive survey on optical remote sensing instrument used for terrestrial static/kinematic, airborne and space image acquisition systems. For more information on imaging and ranging instruments it is suggested to read van Blyenburgh (2013) where 406 instruments are identified.

The UAVs are equipped with a modular set of sensors, selected depending on the purpose of the mission. In this section a short description of electromagnetic spectrum characteristics and examples of optical and radio-frequency (RF) sensors (Table 2 and Table 3 ) used to obtain images will be introduced.

\section{Visible Band $(0.4-0.7 \mu \mathrm{m})$}

Visible band optics operates in the same spectral range as the human eye. Multiple photodetectors are tuned to different wavelengths inside the visible spectra to acquire color imagery. Most commonly used detectors are generally red, green and blue. Those are called primary colors, as no single primary color can be formed from the other two. All other colors are combinations of green, red and blue in varied proportions. Color imaging systems show various disadvantages. One of the biggest limitations of the system is its poor night-vision performance. To obtain satisfactory results, the imagined object has to be illuminated by visible light. The source of it can be either natural from the sun, or from an artificial source such as searchlight. Another limitation appearing during use of color cameras is their sensitivity to low light conditions.

Infrared (IR) $(0.7 \mu \mathrm{m}-1 \mathrm{~mm})$

The part of the electromagnetic spectrum that people come across mostly, during everyday life is infrared light. Even though it is not visible to human eyes it can be felt as heat. Infrared can be divided into following sub-division: nearinfrared (NIR, $0.7-1 \mu \mathrm{m}$ ), short-wavelength infrared (SWIR, 1 - $3 \mu \mathrm{m})$, mid-wavelength infrared (MWIR, 3 - $6 \mu \mathrm{m}$ ), longwavelength infrared (LWIR, $6-14 \mu \mathrm{m})$ and far-infrared (15$1000 \mu \mathrm{m})$. A wavelength of between 3.5 and $20 \mu \mathrm{m}$ refers to thermal infrared, though for remote sensing applications the range vary between 8 to $13 \mu \mathrm{m}$. Objects that have a temperature greater than absolute zero emit thermal infrared energy, which is commonly known as "heat". All the features on the landscape such as water, soil, vegetation, ice or people emit thermal infrared electromagnetic radiation.

Radar Imagery Bands $(1 \mathrm{~mm}-1 \mathrm{~m})$

Microwave wavelengths, compared to visible and infrared ones, are long which provide special properties that are significant for remote sensing. Longer wavelength microwave radiation can operate under almost all weather and environmental conditions, such as heavy rain, dust, haze or clouds as well as operate during day and night.

\subsection{Ground control stations (GCSs)}

Ground Control Stations play a very important role in unmanned aerial systems, probably as important as the unmanned aircraft. GCSs may be either stationary or transportable software/hardware devices which are used to command and monitor unmanned aircraft.

Small UAS GCSs are constructed from a computer and a small ground terminal. At this point it is important to mark that the control segments do not have to be positioned on the ground. Other control segment types are represented by submarine control station, ground-vehicle control station or airborne control station.

Computers used as GCSs can take different types of devices such as PDA, laptop computer, a wearable computer or several transit cases full of equipment. The systems can take various configurations, from simple with an antenna attached to a laptop computer to more complex/complicated like rat's nest with computers, electronics boxes, monitors, antennas, cables and joysticks.

\subsection{Launch and recovery equipment}

The main role of launch and recovery elements (LRE) is to coordinate air traffic in the neighborhood of the airfield. Communication between an operator in the LRE and air traffic control (ATC) is necessary to receive permission to take-off and land as well as to make sure that airspace is safely shared by both manned and unmanned aircrafts. A dedicated LRE is not destined to provide payload control functionality, but if properly equipped may be used as LOS ground station.

\section{EXAMPLES OF UAS IN MARITIME SURVEY}


Unmanned aerial systems have been used widely for many diverse applications. In the war time maritime UAS is being used to assist in the destruction of enemy naval forces, help to defend the coast lines as well as support ground operations. During the peace time maritime UAV systems are used to protect borders, support search and rescue operations, track mammals, evaluate the condition of drilling platforms, detect ships including illegal vessels and monitor maritime environments where hazardous substances such as red tide and oil spill can be present, classification (vessels, oil slick, iceberg, etc.).

UAVs has found application in hurricane forecast. NOAA has been sending UAV into the eye of a hurricane for more than 50 years, gathering data directly from the center of the phenomena. These missions, risky for manned aircraft, can be run via UAVs. Work on improving unmanned systems in terms of hurricane monitoring are constantly conducted. In 2016 NOAA announced the successful improvement of the Coyote Unmanned Aircraft System on which they worked with Raytheon (research.noaa.gov, 2016). The goal of the Coyote program is to build a system able to collect data about pressure, temperature and wind below 3,000 feet, where it is not safe to fly for manned vehicles. In 2007, an Aerosonde UAV was sent to gather real-time data about the near surface of hurricane Noel for $7,5 \mathrm{~h}$, where wind reached gusting speed around $115 \mathrm{~km} / \mathrm{h}$. As the total mission duration was more than 17 hours, it set the record for data gathered and duration.

The project RAVEN (Remote Aerial Vehicle for Environmentmonitoring) was held to develop a Beyond Line of Sight (BLOS) technology to effectively monitor maritime missions in Canada's coastal environment (O'Young and Hubbard, 2007). The main purpose of the project is to develop techniques to protect environment and national security and safety under extreme weather conditions using long endurance UAV. To perform the project the Aerosonde UAV was used. It is a $15-\mathrm{kg}$ unmanned aerial vehicle with a wingspan of $3 \mathrm{~m}$. The maximum payload that can be attached to a vehicle stands at $5 \mathrm{~kg}$ for a $10 \mathrm{~h}$ endurance. The sensors used during the project were high definition digital cameras and videos. Images form the sensors were transmitted directly through a satellite phone such as the Iridium. Another part of the payload attached to the aerial vehicle was a small SAR imaging radar which was constructed at the Bingham Young University and provided by them to the RAVEN project.

Tekever AR5 Life Ray Evolution is a Portuguese unmanned aerial vehicle that was selected in 2014, following the award from the European Maritime Safety Agency and European Space Agency, to be used in the testing of Europe's first UAV maritime surveillance system. In the Rapsody project, UAV has been used to test two various scenarios. First, search and rescue, and second related to pollution and oil spill monitoring over the Mediterranean and North seas as well as over the Atlantic. The UAV wingspan is $4.4 \mathrm{~m}$, its endurance is between 8 to $12 \mathrm{~h}$ and can carry a payload up to $50 \mathrm{~kg}$.

Leira et al (2015) perform an experiment on a low-cost fixedwing UAV for ship detection, where a total flying weight is a maximum of up to $4 \mathrm{~kg}$. A machine vision system designed to detect and track objects found on the water surface in real-time uses a thermal imaging camera joined with on-board processing power. The payload used in this project contains an autopilot (ArduPilot, online website) responsible for flight control, an analog thermal imaging camera (FLIR Tau2 336, online website) as an imaging sensor and a single on-board computer
(PandaBoard, online website) which was used to process data on-board. The analog thermal video feed was converted to a digital video stream by an analog digital converter (Axis M7001, online website). Last component of the payload was a communication link (Ubiquiti Rocket M5, online website) to the ground station.

\section{KEY INDICATORS FOR UAV AND PAYLOAD SELECTION FOR MARITIME MONITORING}

Water around the world varies in many aspects. Its geographical location as well as climate characteristics are factors which has to be considered while choosing aerial vehicle for maritime missions.

\section{$\underline{\text { Selection indicator }}$}

Selection of UAV for maritime missions should take into account the following principles: reliability, meet the maritime supervision requirements, be easy to manage and finally its price should be reasonable (Gao, X., et al., 2014).

- Radius of mission - waters that can be monitored includes costal seas, area far from the coast, inland waters and ports.

- Flying speed - speed with which unmanned vehicles can fly may have significant influence on the mission (wide range of monitoring area)

- Payload weight - payloads used during missions play major role in maritime monitoring. The smaller the UAV the lighter the payload that can be attached to the aircraft. Depending on the distance and size of the area of interest, different UAV and hence, different payloads can be used. For example, for areas near coast and ports, small range aircrafts with load capability between 3 to $50 \mathrm{~kg}$ might be an appropriate choice. On the other hand, for middle distance missions, payload attached to the UAV is usually heavier (more than 50kg) which is related to the mission characteristics. Finally, long distance missions required different UAV with payload no less than $100 \mathrm{~kg}$.

- Endurance - depending on the mission requirements, different endurance of UAV is necessary to successfully complete the task.

- Data link requirements - real-time monitoring indicates the ability for the system to send back sensing data in the real time. Additionally, data links are exposed to different disturbing noises. Therefore, it is important to configure and manage data links reasonably to strengthen its anti-interference ability (Lu et al., 2013).

- Other properties - due to specific weather and environment conditions that may occur during maritime missions (ex. strong wind) it is important to use equipment which is water and salt resistant, have good property of wind resistance etc. This plays an important role to ensure safety during a mission.

\section{$\underline{\text { Payload selection for maritime mission }}$}

Payloads are main actors for maritime UAV missions. Different purposes of monitoring sea water demand different payloads. On the market most common UAV sensors are electromagnetic spectrum sensors, gamma ray sensors, and chemical or biological sensors. Through electromagnetic sensors mostly 
used are the ones operating in the visual spectrum, infrared (or near infrared) and radar systems. Sensors operating in ultraviolet or microwave might be used as well, but are not common (Volpe Center, 2013). One of the most important requirements while choosing sensors is to meet certain performance and functions defined in mission specifications. For example electro-optical pod and spectral images can be used to track, monitor and search small objects (vehicles, vessels) as well as detect oil spill. Microwave radiometers can be used for oil spill detection similarly to fluorescence radar and microwave radar. The last one can also be used to detect vessels for a large monitored area. Electro-optical pod is represented by wide range products which vary depending on resolution ratio, shooting distance and stability. Spectral imagery can be divided into ultraviolet, infrared and multispectral sensors. First two sensors are well known for their usefulness to detect oil spill. Multispectral sensor has the advantage over them, as it can operate in ultraviolet, visible and infrared range of the spectrum at the same time. What is more, sensor characteristics should be compatible with the specific type of UAV (its size and the payload capability should be taken into consideration). As mission tasks can vary significantly and hence need to use different sensors, it is important for a system to be easily dismounted and combined. Reckless performance of the actions mentioned above may cause significant damage to unmanned aircraft. Finally, sensors for maritime missions should be reliable in terms of technical performance. Weather conditions at the investigation area can change frequently and significantly which demand the adaptation to unfavorable weather conditions as well as waterproofness.

\section{SUGGESTIONS OF UAVS AND SENSOR PAYLOADS FOR SELECTED MARITIME MISSIONS}

One of the most important stage of performing monitoring, detection, reconnaissance of maritime environment using UAS is careful study of requirements and assumptions of a mission. Weather conditions are very important factor while choosing unmanned aircraft for maritime missions. Strong wind that may appear frequently has a great influence on UAV stability during a flight. As mentioned in Part 4 of the article, many question have to be answered and many factors have to be taken into consideration. In this part, aerial vehicle and sensing payload are suggested for ship, oil spill and red tide detection.

\section{$\underline{\text { Ship detection }}$}

Ship detection plays important role in security and surveillance of maritime environment. It helps finding illegal ships such as fisheries ships. In this case two sensor payloads are suggested. One is electro-optical camera such as Canon 5D Mark $(0.9 \mathrm{~kg})$ another is thermal camera such as Tau 2640 from FLIR company. Both were successfully used for ship detection ( $\mathrm{Xu}$, C., et al, 2014; Leira, F.S., et al, 2015 respectively). For an aerial vehicle, MD4-300 from Microdrones company is suggested. This drone has max. payload up to $4 \mathrm{~kg}$, operates in $57 \mathrm{~km} / \mathrm{h}$ with flying time up to 45 .

\section{Oil Spill}

Oil spill monitoring and detection is very important in terms of searching for water environment pollution. To detect one either combination of multispectral optical and thermal sensors or active microwave - radar are suggested. First mentioned method, integration of sensors, compensate limitations of single configuration. For example UV allows for sensing thin oil, while IR sense think oil spill. Radar on the other hand, detect location and extent and can operate during day and night, through cloud, mist and fog. For the first option, combination of multispectral camera MiniMCA-6 from Tetracam and thermal camera Miracle 3707K-25 from Thermoteknix System Ltd. can be integrated. Then it comes to radar NanoSAR B from IMSAR is recommended mostly due to its low weight. Suggested sensors can be attached to mini UAV such as SpyLite from BlueBird AeroSystems. Its characteristics are as follow: max. takeoff weight $-9.5 \mathrm{~kg}$, wing span $-2.75 \mathrm{~m}$, length $-1.35 \mathrm{~m}$, endurance from 3 to 4 hours (depending on mission, environment and payload), airspeed $60-120 \mathrm{~km} / \mathrm{h}$ and control range up to $50 \mathrm{~km}$.

\section{$\underline{\text { Red Tide }}$}

Red tide phenomena has a great negative impact on water conditions which results in death of fishes and other sea mammals as well as birds. It also may have bad impact on human health. It is hard to evaluate the exact size of the phenomena. In 2014 a really wide red tide, stretching $96 \mathrm{~km}$ wide and $144 \mathrm{~km}$ long, was spotted around $32 \mathrm{~km}$ from the southwestern coast of Florida. Even though it was too far away to bother beachgoers, it shows how serious it can be. That is why fast detection and monitoring is very important. For that reason mini UAV could be used, which is represented, for example, by RQ-11B Raven form AeroVironment company. This aircraft range is $10 \mathrm{~km}$ endurance between $60-90 \mathrm{~min}$, speed vary from $32-81 \mathrm{~km} / \mathrm{h}$ and the operating altitude is between 30-152 m. As a sensor payload, multispectral camera is suggested, for example Condor-5 UAV-285 from Quest Innovation.

As it is hard to propose specific unmanned aerial vehicle (ex. depends on area of interest, endurance and altitude) and payload sensor (ex. depends on the maximum payload of the UAV) without knowing exact and precise mission requirements, suggestions above are just one from many configurations that could be taken into consideration.

\section{CONCLUSION}

In this paper is a review of basic components used for building unmanned aircraft systems (UAS), suggestions on what to take into consideration while choosing aircraft and payload sensors as well as a few examples of systems already used for maritime applications is introduced. Nowadays, the role of UAV systems is growing in importance for civilian missions. This has led to an increase in development and exploration of unmanned aircraft systems. One of the advantages UAVs have over manned aircrafts, is acquiring high-resolution remote-sensing data at greater versatility and at lower cost. On the market a wide range of different types of vehicles are available, from large to small, rotor or fixed wing, and its price varies from several hundreds to tens of thousands of dollars (which also includes instrument payloads).

With increasing interest and use of unmanned aircraft systems, a progress in development of miniaturized sensors as well as advances in materials science can be spotted. A further challenge is increasing memory and data storage and computing power of sensors. A very important aspect of future work on remote sensing sensors is standardization. Possibility to adapt data format widely, data bus can contribute to a reduction of costs and increase availability of different plug and play sensors.

Balloons and blimps are a great source of data for coastal monitoring and mapping due to its stable instrument platform. 
A camera attached to a blimp or balloon (which is launched from a vessel performing oil recovery) can collect data of the area of interest in real time. This has an impact on cost reduction and oil recovery rates (Klemas, V., 2015).

UAVs successfully fill the gap in maritime environment monitoring, however its increasing use draws attention to legal aspects related to wide use of UAVs. One of the biggest safety issues is to enter unmanned aircrafts into non-segregated airspace. This is due to the strict requirements of safety for manned aircrafts (Pereira et al., 2009). Williams (2004) in his report analyze unmanned aircraft accidents. In the report, he states that human factor vary from $21 \%$ to $68 \%$ in causing UAV accidents, yet for most of the aircraft systems, more casual factor that the human error was electromechanical failure.

In future, UAV systems will have even more to offer than now. Technological development, law regulations will result in even broader use of Unmanned Aerial Vehicles in maritime applications.

\section{AKNOWLEGMENTS}

This research was a part of a project titled "Base Research for Building Wide Integrated Surveillance System of Marine Territory" founded by the Ministry of Oceans and Fisheries, Korea.

\section{REFERENCES}

Apm autopilot suite, 2014, [Online], Available: http://www.ardupilot.com/

Axis m7001, 2011, [Online], Available: http://www.axis.com/en/products/camm7001lindex.htm

Colomina, I., Molina, P., 2014, Unmanned Aerial Systems for Photogrammetry and Remote Sensing: A Review, ISPRS Journal of Photogrammetry and Remote Sensing 92, pp. 79 - 97

Flir tau2 336, 2011, [Online], Available: http://www.flir.com/cvs/cores/view/id=S4717

Gao, X., Mu, X., Sun, D., Liu, S., 2014, Study on Selection of Maritime Supervision Unmanned Aerial Vehicle and Mission Payloads, CICTP: Smart and Sustainable Multimodal Transportation Systems

Gundlach, J., 2012, Design Unmanned Aircraft Systems: A Comprehensive Approach, American Institute of Aeronautics and State University, Blacksburg, Virginia

Gupta, S.G., Ghonge, M.M., Jawandhiya, P.M., 2013, Review of Unmanned Aircraft System (UAS), International Journal of Advanced Research in Computer Engineering \& Technology (IJARCET), Vol. 2, Issue 4

Klemas. V.V., 2015, Coastal and Environmental Remote Sensing from Unmanned Aerial Vehicle: An Overview, Journal of Coastal Research, Vol. 31, No. 5, 1260-1267

Leira, F., S., Johansen, T., A., Fossen, T., I., 2015, Automatic detection, classification and tracking of objects it the ocean surface from UAVs using a thermal camera,

Lu, B.D., Liu, C.S and Huang Z.R., 2013, Research into the jamming methods to UAV measurement and control system, Shipboard electronic Countermeasure, 36, 24-27
Mueller, T. J., 2001, Fixed and Flapping Wing Aerodynamics for Micro Air Vehicle Applications

NOAA, 2016,

http://research.noaa.gov/News/NewsArchive/LatestNews/TabId /684/ArtMID/1768/ArticleID/11569/NOAA-and-Raytheonimprove-unmanned-aircraft-to-collect-hurricane-weatherdata.aspx

Nonami, K., Kendoul, F., Suzuki , S., Wang, W., Nakazawa, D., 2010, Autonomous Flying Robots, Unmanned Aerial Vehicles and Micro Aerial Vehicles\|, ISBN 978-4-431-53855-4, Springer

O'Young, S., Hubbard, P., 2007, RAVEN: A maritime surveillance project using small UAV, IEEE Conf. on Emerging Technologies \& Factory Automation, pp. 904-907

Pandaboard es., 2011, [Online], Available : http

://www.pandaboard.org/

Pereira, E., Bencatel, R., Correira, J., Felix, L., Goncalves, G., Morgano, J., Sousa, J., 2009, Unmanned air vehicles for costal and environmental research, In: da silva, C.P (ed), Proceedings of the ICS, Journal of Coastal Research, Special Issue No. 56, pp. $1557-1561$

Remondino, F., 2011, Heritage recording and 3D modeling with photogrammetry and 3D scanning Remote Sens., 3, pp. 11041138

Sawicki. P., 2012, Unmanned Aerial Vehicles in Photogrammetry and Remote Sensing - State of the Art and Trends, Archive of Photogrammetry, Cartography and Remote Sensing, Vol 23, pp 365 - 376

Skrzypietz, T., 2012, Unmanned Aircraft Systems for Civilian Missions, Brandenburg Institute for Society and Security

UAV Classification Table, http://www.globalsecurity.org/military/world/europe/aircraftuav-class.htm

Ubiquiti rocket mS, 2011, [Online]. Available: http://www.ubnt.com/airmax/rocketm/

Van Blyenburgh, P., 2013. 2013-2014 RPAS Yearbook: Remotely Piloted Aircraft Systems: The Global Perspective 2013/2014. Technical Report. UVS International. Paris, France

Volpe National Transportation Systems Center, 2013, Unmanned aircraft Systems (UAS) Service Demand 20152035, https://fas.org/irp/program/collect/service.pdf

Williams, K.W., 2004, A summary of Unmanned Aircraft Accident/Incident Data: Human Factors Implications, U.S. Department of Transportation, Federal Aviation Administration 


\begin{tabular}{|c|c|c|c|c|c|c|c|}
\hline CLASS & CATEGORY & $\begin{array}{c}\text { WEIGHT } \\
\mathrm{W}_{\mathrm{TO}}\end{array}$ & $\begin{array}{l}\text { OPERATING } \\
\text { ALTITUDE }\end{array}$ & $\begin{array}{c}\text { RADIUS OF } \\
\text { MISSION }\end{array}$ & ENDURANCE & SPEED & $\begin{array}{c}\text { EXAMPLE } \\
\text { PLATFORM }\end{array}$ \\
\hline & & $\mathrm{kg} / \mathrm{lb}$ & $\mathrm{m} / \mathrm{ft}$ & $\mathrm{km} / \mathrm{mile}$ & hours & $\mathrm{km} / \mathrm{h}(\mathrm{kt})$ & \\
\hline \multirow{3}{*}{$\begin{array}{c}\mathrm{I} \\
\mathrm{W}_{\mathrm{TO}}<150 \mathrm{~kg} \\
\mathrm{~W}_{\mathrm{TO}}<330 \mathrm{lb}\end{array}$} & Micro & $\begin{array}{l}\text { up to } \\
2 / 4,41\end{array}$ & Up to $61 / 200$ & Up to $5 / 3,1$ & Up to 1 & $\sim 70 / 38$ & $\begin{array}{l}\text { Black } \\
\text { Widow }\end{array}$ \\
\hline & Mini & $\begin{array}{l}\text { up to } \\
20 / 44,1\end{array}$ & $\begin{array}{c}\text { Up to } \\
914 / 3000 \\
\end{array}$ & Up to $25 / 15,5$ & Up to 2 & & DH3, Raven \\
\hline & Small & $>20 / 44,1$ & $\begin{array}{c}\text { Up to } \\
1524 / 5000\end{array}$ & Up to $50 / 31,1$ & Up to 10 & $\sim 93 / 50$ & $\begin{array}{c}\text { Luna, } \\
\text { Hermes } 90\end{array}$ \\
\hline $\begin{array}{c}\mathrm{II} \\
\mathrm{W}_{\mathrm{T} 0}<600 \mathrm{~kg} \\
\mathrm{~W}_{\mathrm{T} 0}<1323 \mathrm{lb} \\
\end{array}$ & Tactical & Up to 150 & $\begin{array}{c}\text { Up to } \\
3048 / 10000\end{array}$ & Up to $200 / 124,3$ & Up to 24 & $\sim 231 / 125$ & $\begin{array}{l}\text { Aerostar, } \\
\text { Ranger, } \\
\text { Sperwer }\end{array}$ \\
\hline III & & & & & & & \\
\hline $\begin{array}{c}\mathrm{W}_{\mathrm{T} 0}>600 \mathrm{~kg} \\
\mathrm{~W}_{\mathrm{T} 0}>1323 \mathrm{lb}\end{array}$ & MALE & & $\begin{array}{c}\text { Up to } \\
13716 / 45000\end{array}$ & $>1000 / 621,4$ & Up to 48 & $\sim 250 / 135$ & $\begin{array}{l}\text { Predator A, } \\
\text { Predator B }\end{array}$ \\
\hline $\begin{array}{c}\mathrm{W}_{\mathrm{T} 0}>600 \mathrm{~kg} \\
\mathrm{~W}_{\mathrm{T} 0}>1323 \mathrm{lb}\end{array}$ & HALE & & $\begin{array}{c}\text { Up to } \\
19812 / 65000\end{array}$ & $>1000 / 621,4$ & Up to 48 & $\sim 250 / 135$ & $\begin{array}{l}\text { Global } \\
\text { Hawk }\end{array}$ \\
\hline
\end{tabular}

Table 1. Possible Classification of UAV (Gupta, S.G. et al, 2013; Sawicki, P., 2012; Gundlach, J., 2012; http://www.globalsecurity.org/military/world/europe/aircraft-uav-class.htm)

\begin{tabular}{|c|c|c|c|c|c|}
\hline $\begin{array}{l}\text { Manufacturer } \\
\text { and model }\end{array}$ & $\begin{array}{c}\text { Size } \\
\left(\mathrm{mm}^{2}\right)\end{array}$ & $\begin{array}{l}\text { Resolution } \\
\text { (Mpx) }\end{array}$ & $\begin{array}{l}\text { Pixel size } \\
(\mu \mathrm{m})\end{array}$ & $\begin{array}{c}\text { Weight } \\
(\mathrm{kg})\end{array}$ & Additional information \\
\hline \multicolumn{6}{|c|}{ Camera category: visible band cameras } \\
\hline Sony NEX-7 & $\begin{array}{c}23.5 \mathrm{x} \\
15.6\end{array}$ & CMOS 24.3 & 3.9 & 0.35 & $\begin{array}{l}\text { Frame rate (fps): } 2.3 ; \text { speed }\left(\mathrm{s}^{-1}\right) \text { : } \\
4000 \text { (focal plane shutter) }\end{array}$ \\
\hline $\begin{array}{l}\text { Hasselblad H4D- } \\
60\end{array}$ & $\begin{array}{c}53.7 \mathrm{x} \\
40.2\end{array}$ & CCD 60 & 6.0 & 1.8 & $\begin{array}{l}\text { Frame rate (fps): } 0.7 ; \text { speed }\left(\mathrm{s}^{-1}\right) \text { : } \\
800 \text { (leaf shutter) }\end{array}$ \\
\hline \multicolumn{6}{|c|}{ Camera category: multispectral cameras } \\
\hline $\begin{array}{c}\text { Quest Innovation } \\
\text { Condor-5 UAV- } \\
258\end{array}$ & $\begin{array}{c}10.2 \mathrm{x} \\
8.3\end{array}$ & CCD 1.4 & $7.5 \times 8.1$ & 0.8 & Spectral range (nm): $400-1000$ \\
\hline $\begin{array}{c}\text { Tertracam } \\
\text { MiniMCA-6 }\end{array}$ & $\begin{array}{c}6.66 \mathrm{x} \\
5.32\end{array}$ & CMOS 1.3 & $5.2 \times 5.2$ & 0.7 & Spectral range (nm): $450-1050$ \\
\hline \multicolumn{6}{|c|}{ Camera category: hyperspectral cameras } \\
\hline $\begin{array}{c}\text { Headwall } \\
\text { Photonics Micro- } \\
\text { Hyperspec X- } \\
\text { series NIR }\end{array}$ & $\begin{array}{l}9.6 \mathrm{x} \\
9.6\end{array}$ & InGaAs & 30 & 1.025 & $\begin{array}{l}\text { Spectral range (nm): } 900-1700 ; \\
\text { spectral bands: } 62 ; \text { spectral } \\
\text { resolution: } 12.9 \mathrm{~nm}\end{array}$ \\
\hline \multicolumn{6}{|c|}{ Camera category: thermal cameras } \\
\hline FLIR TAU 2640 & $\begin{array}{c}10.8 \mathrm{x} \\
8.7\end{array}$ & $\begin{array}{l}\text { Uncooled } \\
\text { VOx } \\
\text { Microblomete } \\
\text { r } 640 \times 512 \\
\end{array}$ & 17 & 0.07 & $\begin{array}{l}\text { Spectral range }(\mu \mathrm{m}): 7.5 \times 13.5 \text {; } \\
\text { thermal insensitivity }(\mathrm{mK}) \leq 50\end{array}$ \\
\hline
\end{tabular}

Table 2. Common or/and representative sensors for UAS (Colomina, I., Molina, P., 2014)

\begin{tabular}{|c|c|c|c|c|}
\hline $\begin{array}{c}\text { Manufacturer } \\
\text { and model }\end{array}$ & weight & Spectral bands & $\begin{array}{c}\text { Transmitted } \\
\text { power }(\mathrm{W})\end{array}$ & Resolution (m) \\
\hline $\begin{array}{c}\text { IMSAR } \\
\text { NanoSAR B }\end{array}$ & 1.58 & $\mathrm{X}$ and Ku & 1 & Between 0.3 - 5 \\
\hline $\begin{array}{c}\text { NASA JPL } \\
\text { UAVSAR }\end{array}$ & 200 & $\mathrm{~L}$ & 2000 & 2 \\
\hline
\end{tabular}

Table 3. Common or/and representative SAR radars for UAS 